Article

\title{
Extended Prescribing Roles for Pharmacists in Poland-A Survey Study
}

\author{
Jagoda Miszewska $^{1}$, Natalia Wrzosek ${ }^{2}$ and Agnieszka Zimmermann ${ }^{2, *(\mathbb{D})}$ \\ 1 Students' Scientific Circle of Pharmaceutical Law, Department of Medical and Pharmaceutical Law, \\ Medical University of Gdansk, 80-210 Gdansk, Poland; jagodam@gumed.edu.pl \\ 2 Department of Medical and Pharmacy Law, Medical University of Gdansk, 80-210 Gdansk, Poland; \\ natalia.wrzosek@gumed.edu.pl \\ * Correspondence: agnieszka.zimmermann@gumed.edu.pl; Tel.: +48-58-349-14-47
}

check for updates

Citation: Miszewska, J.; Wrzosek, N.; Zimmermann, A. Extended Prescribing Roles for Pharmacists in Poland-A Survey Study. Int. J. Environ. Res. Public Health 2022, 19, 1648. https://doi.org/10.3390/ ijerph19031648

Academic Editor: Aziz Rahman

Received: 15 December 2021

Accepted: 29 January 2022

Published: 31 January 2022

Publisher's Note: MDPI stays neutral with regard to jurisdictional claims in published maps and institutional affiliations.

Copyright: (C) 2022 by the authors. Licensee MDPI, Basel, Switzerland. This article is an open access article distributed under the terms and conditions of the Creative Commons Attribution (CC BY) license (https:// creativecommons.org/licenses/by/ $4.0 /)$.

\begin{abstract}
Background: In recent years, a systematic increase in the role and powers of pharmacists has been observed. The COVID-19 pandemic has shown that this is a professional group that is extremely necessary for the smooth functioning of the health care system. One of the important powers of pharmacists is the possibility of issuing prescriptions for both patients in the pharmacy and for themselves and their family members. Polish pharmacists obtained extended entitlements in this field in March 2020. Due to the extension of pharmacists' prescribing rights in Poland, it was decided in this study to determine the current practice of pharmaceutical prescribing, and pharmacists' views on their new duties. Methods: The study used the method of a questionnaire, which was distributed to all pharmacists actively working in Poland. During the study, 309 completed questionnaires were obtained that gathered information about prescriptions written by pharmacists, as well as their opinions related to this entitlement. The results of the survey were analyzed using descriptive statistics. Results: Out of all authorized pharmacists, $75.62 \%$ use the new, extended authorization to issue pharmaceutical prescriptions. About half of them believe their prescriptions should be refundable. Only $11.52 \%$ of respondents do not use the entitlement to issue prescriptions for themselves or their family members. In addition, it was noticed that those who write such prescriptions most often use the fully paid version. Conclusions: Polish pharmacists use the new entitlements willingly but carefully. The legal provisions governing electronic prescription should be clearer. In addition, the idea of continued prescription should be developed as this is the most common reason that pharmacists issue prescriptions.
\end{abstract}

Keywords: pharmacy prescribing; pharmacy legislation; entitlements of pharmacists

\section{Introduction}

Pharmacists are increasingly performing functions in health care systems attributed to independent medical professions. They have the knowledge and competence necessary to prescribe prescription-only drugs on their own. Until April 2020, a pharmaceutical prescription in Poland could be issued only in exceptional cases, as stipulated in Article 96 of the Pharmaceutical Law [1]. A pharmacist could dispense one minimum package size of a medicinal product admitted to marketing in the territory of Poland only in the case of an emergency threat to the patient's health. Because of the uncertainty surrounding the definition of a medical emergency, and because such situations are rare in pharmacy practice, the decision to issue a pharmaceutical prescription was sporadic [2].

The specific types of prescribing among medical professions in Poland are pro auctore and pro familiae. A pro auctore prescription means a prescription for the prescriber, while a pro familiae prescription is issued to the family of the prescriber. The term "family" is used here to mean spouse, cohabiting partner, relations by blood and by affinity in the direct line, and relations by blood in the collateral line up to the third degree of kinship 
in Roman computation [1]. Doubts may be raised by the term cohabitation, which is not statutorily defined. Pro auctore and pro familiae prescriptions were the professional domain of physicians and dentists until nurses and midwives in Poland became eligible for such prescribing on 1 January 2016 [3]. In 2020, Polish pharmacists also became entitled to do so, with the coronavirus pandemic proving to be the turning point. The COVID-19 pandemic has put tremendous pressure on health care systems around the world. Difficult access to physicians has shown how fundamental all medical professions, including pharmacists, are to the functioning of the health care system. The widespread availability of pharmacies means that they are often a patient's first point of contact with the health care provider. In the face of the pandemic, the need for additional pharmaceutical services, which required changes in legal regulations, was recognized in many countries, not only in Poland. For example, the implementation of e-prescribing in Italy and Austria, the possibility of the home delivery of medicines in Portugal and the USA or, as in Canada: authorizing pharmacists to prescribe, sell, or provide controlled substances, e.g., benzodiazepines, in limited circumstances, including allowing pharmacists to extend and renew prescriptions, as well as to transfer prescriptions to other pharmacists [4].

Currently, the entitlements of Polish pharmacists related to prescribing have been extended, with the introduction of legal regulations related to COVID-19 prevention in March 2020 [5]. Under this legislation, from 1 April 2020, a pharmacist has the ability to issue a prescription for any health risk to a patient [6]. The ongoing COVID-19 pandemic forces pharmacists to reinvent their roles and intensifies the pharmaceutical practice, whereas great shortages of the health care workforce these days make this initiative rational and helpful [7]. In light of the above-mentioned amendments, a medicinal product may be issued by a pharmacist in an amount sufficient for up to 180 days when an electronic prescription is used. As before, a pharmaceutical prescription is filled with a $100 \%$ payment. Medicinal products containing narcotic drugs and psychotropic substances are still excluded from pharmaceutical prescribing. A novelty in the entitlements of pharmacists is the possibility of issuing pro auctore and pro familiae prescriptions. Such a prescription may be reimbursable and may be issued by anyone in the pharmacy profession, not necessarily in a community pharmacy. Moreover, pharmacists are obliged to keep records of issued pro auctore and pro familiae prescriptions. The list of pro auctore and pro familiae prescriptions should contain information required by law: personal ID number, the diagnosis of the illness, health problem or injury, the International Nonproprietary Name (INN) or trade name of the medicine, the form and the dose of the prescribed drug, and the quantity. It is also very important to record the dosage regimen.

Based on data of the Ministry of Health collected between 1 June 2020 and 30 September 2020, the average number of prescriptions issued by pharmacists is gradually increasingnot only those for patients, but also for the pharmacists themselves and their families [2]. However, there are no data regarding what situations the prescriptions relate to-whether the majority of the prescribed medicines are those which are suddenly needed (life-saving drugs) or those used as part of a continuation of long-term therapy. The next stage of development of pharmaceutical prescribing in Poland will be a repeat prescription (from 16 January 2022) which will be possible for a pharmacist to issue within the scope of pharmaceutical care referred to in the Act of 10 December 2020 on the Pharmacist Profession [8].

Pharmaceutical prescribing is practiced worldwide based on different models. The basic division is independent prescribing (IP) or dependent prescribing. There is also collaborative prescribing, where the pharmacist's prescribing is mainly based on the continuation of a doctor's prescription [9]. An intermediate scheme between the models discussed above is supplementary prescribing (SP), which involves a voluntary partnership between a physician and a pharmacist (or nurse) to implement an individual clinical management plan (CMP) with patient consent. In this system, the pharmacist has access to the patient's clinical data and may participate in their treatment process; moreover, the pharmacist may issue reimbursement prescriptions or modify the pharmacotherapy suggested by the physician. These solutions operate successfully in the United Kingdom [10]. Currently, 
in Poland there is no classification of pharmaceutical prescribing models; however, the current pharmacists' entitlements are most similar to the idea of independent prescribing (IP). In light of the Act of 10 December 2020 on the Pharmacy Profession, there will also be a repeat prescription [8], so this change will presumably lead to collaborative prescribing, as we are still waiting for detailed guidelines on such prescriptions.

\section{Aim of the Study}

Due to the extension of pharmacists' prescribing rights in Poland, it was decided in this study to determine the current practice of pharmaceutical prescribing, and pharmacists views on their new duties. The study aimed to assess the opinions of Polish pharmacists on prescribing in the context of the legal changes, and their opinions on clarifying certain legal inconsistencies in this area. Moreover, it sought to define pharmacists' concerns related to pharmaceutical prescribing.

\section{Materials and Methods}

\subsection{Research Tools}

Due to the lack of available surveys concerning pharmaceutical practices in the field of prescribing, and opinions of Polish pharmacists about the self-administration of prescriptions, a self-designed questionnaire was constructed based on articles referring to experiences with pharmaceutical prescribing in other countries [11-13]. The Survey questionnaire can be found at the Supplementary Materials. In addition, publications referring to other health professionals, e.g., nurses, were used. The final form of the questionnaire was adjusted to realities resulting from the current legal status in Poland. To create the questionnaire, we used a content validity measurement: during the survey design, 5 scientists from the Sociology Department were asked to rate the survey questions and categorize them as "essential", "useful", or "not necessary". For each question, the Content Validity Ratio was calculated, and the results ranged from 0.6 to 0.9 .

The study was carried out by means of a diagnostic survey, using the questionnaire technique. The survey form consisted of 19 closed and semi-open questions. The first part of the questionnaire consisted of 15 questions and was designed to gather information about prescriptions written by pharmacists, as well as their opinions related to this entitlement. The first seven questions sought to determine whether pharmacists issued pharmaceutical prescriptions and pro auctore/pro familiae prescriptions-including whether they were reimbursement or fully paid prescriptions. Respondents were given a choice of one of three responses: "yes", "no", or "I do not remember". The average number of prescriptions dispensed per month was then requested and the responses were given in numerical ranges. The construction of this question was based on a study conducted in Wales [13]. The respondents were then asked to specify what the prescriptions they had issued were for by indicating the main reason for doing so (continuation of therapy for a chronic disease, lifesaving, self-diagnosis, request from a patient or family member, other answer). A Likert scale (definitely no, rather no, hard to say, rather yes, definitely yes) was used in the question on the perception of current regulations as clear and transparent. The last six questions sought to uncover pharmacists' opinions on the functionality of the current legal regulations, e.g., addressing the lack of reimbursement of pharmaceutical prescriptions. The next question raised the issue of magistral drugs in asking whether pharmacists should be allowed to write prescriptions for them. Respondents were given a choice of answers: "yes", "no", "I have no opinion". The penultimate, 14th question related to feelings of anxiety about prescribing, and respondents who answered "yes" were asked in question 15 to indicate the reason for such feelings. The second part of the questionnaire contained 4 questions relating to the professional status of the respondents, their professional experience (with a choice of a range of years), the place of practicing their profession - with the possibility of indicating this place independently if it was other than a community or hospital pharmacy. The last question of this section asked about the 
location of the pharmacy or workplace by indicating the appropriate population density range of the locality.

\subsection{Study Group}

Pharmacists with a valid license to practice, and entered in the register of pharmacists, participated in the study; no exclusion criteria were applied, because all pharmacists with a license to practice may issue pro auctore and pro familiae prescriptions. Due to the narrow exclusion criteria, the snowball method was used to collect the data. It is a non-random sampling method that recruits participants by other participants.

This method was able to obtain answers from 309 respondents, including 283 pharmacists working in community pharmacies, 6 master pharmacists from hospital pharmacies, and 20 pharmacists practicing in a location other than a pharmacy (hospice, etc.). Managers of community pharmacies accounted for $27.51 \%$ and other pharmacists working in community pharmacies $64.08 \%$ of all respondents, pharmacists working in hospital pharmacies accounted for $1.94 \%$, while no responses were collected from managers of hospital pharmacies. Pharmacists practicing outside of a pharmacy accounted for $6.47 \%$ of the respondents. The most frequently indicated place of practice was a community pharmacy belonging to a large pharmacy chain, which concerned 211 respondents $(74.55 \%)$. In total, 33 respondents came from small chain pharmacies, while 24 were from individual pharmacies.

\subsection{Study Settings}

The survey, using a questionnaire technique, was conducted among pharmacists from 3 January 2021 to 21 February 2021. The survey form was created electronically and distributed via email and social media, including being shared on a pharmacy staff internet group. Moreover, with the consent of the Dean of the Faculty of Pharmacy of the Medical University of Gdansk, the survey was conducted among doctoral students and academic teachers of this faculty.

\subsection{Ethical Issues}

No intervention was performed on the research participants (non-invasive research) and therefore the consent of the bioethics committee was not required. The full confidentiality and anonymity of the respondents was maintained during the study. All participants gave their informed and voluntary consent prior to participation.

\subsection{Statistical Analysis}

Microsoft Excel 365 and Statistica 13.3 were used to process the results of the study. The statistical analysis was performed using Pearson's chi square test. Differences of $p<0.05$ were considered statistically significant.

\section{Results}

Respondents who reported professional experience of less than five years accounted for $39.16 \%$. On the other hand, $28.48 \%$ of the responses are from pharmacists with professional experience ranging from 5 to 10 years and $27.18 \%$, with experience ranging from 10 to 20 years. The fewest responses were received from respondents with work experience longer than 20 years $(5.18 \%)$.

The first question of the survey was to determine whether pharmacists, with the awareness of their extended rights in this area, use the possibility of prescribing drugs. Taking into account that pharmacists working in a hospital pharmacy or in a place other than a pharmacy do not have the possibility to issue a pharmaceutical prescription for patients, only the responses of pharmacists and managers working in community pharmacies (283 respondents) were included in the analysis. In this group, the response was $75.62 \%$ affirmative and $24.38 \%$ negative. Accordingly, almost half of the respondents (49.51\%) believe that a pharmacist should be able to issue reimbursement prescriptions, $39.81 \%$ of 
the respondents have the opposite opinion, while $10.68 \%$ have no opinion on this issue (Table 1).

Table 1. Percentage distribution of respondents' answers to the questions asked in the questionnaire regarding a pharmaceutical prescription issued to a patient in a pharmacy.

\begin{tabular}{|c|c|c|c|}
\hline $\begin{array}{l}\text { Question Asked in the } \\
\text { Survey }\end{array}$ & Answer & All Respondents $(n=309)$ & $\begin{array}{l}\text { Pharmacists and Managers } \\
\text { Working in Community } \\
\text { Pharmacies }(n=283)\end{array}$ \\
\hline \multirow{2}{*}{$\begin{array}{l}\text { Have you issued a } \\
\text { pharmaceutical prescription } \\
\text { (fully paid to the patient) after } \\
\text { the legal changes? }\end{array}$} & Yes & $71.52 \%$ & $75.62 \%$ \\
\hline & No & $28.48 \%$ & $24.38 \%$ \\
\hline Total: & & $100 \%$ & $100 \%$ \\
\hline \multirow{3}{*}{$\begin{array}{c}\text { Should pharmacists be able to } \\
\text { issue reimbursement } \\
\text { prescriptions for patients? }\end{array}$} & Yes & $49.51 \%$ & $47.7 \%$ \\
\hline & No & $39.81 \%$ & $42.05 \%$ \\
\hline & Have no opinion & $10.68 \%$ & $10.25 \%$ \\
\hline Total: & & $100 \%$ & $100 \%$ \\
\hline
\end{tabular}

The vast majority of pharmacists surveyed issued a pro auctore prescription- $83.5 \%$ $(n=258) ; 15.9 \%$ of respondents marked a negative answer $(n=49)$ and two respondents $(0.6 \%)$ could not remember whether they issued such a prescription. Of the 258 respondents who wrote a prescription for themselves, 1 person skipped the questions regarding the payment of prescriptions, i.e., did not mark any of the answers in these questions. For the remaining group $(n=257), 81.3 \%(n=209)$ issued a fully paid pro auctore prescription only, 4 people (1.6\%) only a reimbursement one, and 44 respondents $(17.1 \%)$ issued such a prescription in both the reimbursement and fully paid versions. Respondents were found to be significantly more likely to write a fully paid pro auctore prescription than a reimbursement prescription $(p<0.001)$.

In the case of pro familiae prescriptions, the same order of questions was followedfirstly, the respondent was asked whether he/she had issued the indicated prescription at all, and then whether these prescriptions included reimbursement and fully paid prescriptions, respectively. A pro familiae prescription was issued by $76.4 \%$ of the respondents ( $n=236)$, while $23.3 \%$ of the respondents $(n=72)$ chose the opposite answer and one person marked the "do not remember" option. In order to calculate the percentage of fully paid and reimbursement prescriptions, a group of 233 respondents was used, since 2 respondents claimed not to have issued either fully paid or reimbursement prescriptions in the next two questions. In turn, one person, despite confirming the fact of issuing a pro familiae prescription, skipped the questions specifying the type of payment. In total, 8 respondents (3.4\%) issued prescriptions only for reimbursed drugs and 172 pharmacists decided to write pro familiae prescriptions only with $100 \%$ payment. Study participants who issued pro familiae prescriptions of both payment types accounted for $22.8 \%$ of the group that used the given prescribing method (53 out of 233 individuals) (Table 2). Respondents were found to be significantly more likely to write a pro familiae prescription in the fully paid version than in the reimbursement version $(p<0.001)$. 
Table 2. Distribution of respondents' answers to questions about the pro auctore and pro familiae prescriptions issued.

\begin{tabular}{|c|c|c|c|}
\hline Question Asked in the Survey & Answer & $\%$ & Frequency \\
\hline \multirow{3}{*}{$\begin{array}{l}\text { Have you been issuing pro } \\
\text { auctore prescriptions? }\end{array}$} & Yes & $83.5 \%$ & 258 \\
\hline & No & $15.9 \%$ & 49 \\
\hline & I do not remember & $0.6 \%$ & 2 \\
\hline Total: & & $100 \%$ & 309 \\
\hline \multirow{3}{*}{$\begin{array}{c}\text { With what payment method do } \\
\text { you issue pro auctore } \\
\text { prescriptions? }\end{array}$} & Fully paid only & $81.3 \%$ & 209 \\
\hline & Reimbursement only & $1.6 \%$ & 4 \\
\hline & $\begin{array}{l}\text { Both fully paid and } \\
\text { reimbursement }\end{array}$ & $17.1 \%$ & 44 \\
\hline Total: & & $100 \%$ & 257 \\
\hline \multirow{3}{*}{$\begin{array}{l}\text { Have you been issuing pro } \\
\text { familiae prescriptions? }\end{array}$} & Yes & $76.4 \%$ & 236 \\
\hline & No & 23.35 & 72 \\
\hline & I do not remember & $0.4 \%$ & 1 \\
\hline Total: & & $100 \%$ & 309 \\
\hline \multirow{3}{*}{$\begin{array}{c}\text { With what payment method do } \\
\text { you issue pro familiae } \\
\text { prescriptions? }\end{array}$} & Fully paid only & $72.9 \%$ & 172 \\
\hline & Reimbursement only & $3.4 \%$ & 8 \\
\hline & $\begin{array}{l}\text { Both fully paid and } \\
\text { reimbursement }\end{array}$ & $22.5 \%$ & 53 \\
\hline Total: & & $100 \%$ & 233 \\
\hline
\end{tabular}

Based on the results collected, it was found that $11.52 \%(n=36)$ of the study participants did not write either a pro auctore or a pro familiae prescription. Nevertheless, a large number of respondents, i.e., 221 (71.52\%), took advantage of their entitlement by prescribing both for themselves and their family members.

To find out the extent of pharmaceutical prescribing, the study participants were asked to indicate the numerical range of prescriptions written per month. The largest number of respondents $(n=231)$ indicated a range between 1 and 5 , while between 5 and 10 prescriptions per month were issued by 36 people and between 10 and 15 by 14 of the surveyed pharmacists. There were 2 responses each of " $15-20$ " and "over 20 ". The remaining respondents marked the option " 0 " $(n=24)$ (Table 3). No relationship was found between the number of prescriptions (including pro auctore and pro familiae prescriptions) dispensed and the length of the pharmacists' work experience. In addition, there were no significant statistical differences between the number of prescriptions issued in the group of managers and masters of community pharmacies. The question about the reason for prescribing by the pharmacist, regardless of the type of prescription, revealed that most prescriptions were prescribed for the continuation of therapy for chronic diseases $(n=230)$. Prescriptions based on own diagnosis, in the case of a minor illness, were prescribed by 30 respondents, while the same number of people marked the option "at the request of the patient". Only 14 respondents out of a total of 309 did not answer this question. No respondents marked the response "prescriptions for life-saving drugs (e.g., epinephrine, insulin)" to the question. Respondents were then asked to rate the current legislation. According to $44.7 \%$ of respondents, the current regulations are rather clear and transparent, while only $2.6 \%$ answered "definitely yes". For $11.0 \%$ of the respondents, the current regulations are definitely not clear or transparent and $22.3 \%$ of the respondents marked "rather not" to this question. The remaining $19.4 \%$ of responses were "hard to say". There were no significant statistical differences in terms of work experience (in years) or work status regarding this question. In the next question, respondents were asked to give their opinion on the prevalence of prescription abuse by pharmacists. There 
were 198 responses denying that such a phenomenon occurred (64.1\%), and far fewer respondents chose an affirmative response-38 (12.3\%). The answer "do not know" was marked by 73 respondents $(23.6 \%)$ (Table 3$)$.

Table 3. Distribution of respondents' responses to questions about opinions and experiences with prescribing.

\begin{tabular}{|c|c|c|c|}
\hline Question Asked in the Survey & Answer & $\%$ & Frequency \\
\hline \multirow{6}{*}{$\begin{array}{l}\text { How many prescriptions do you } \\
\text { issue on average in a month? }\end{array}$} & 0 & $7.77 \%$ & 24 \\
\hline & $1-5$ & $74.75 \%$ & 231 \\
\hline & $5-10$ & $11.65 \%$ & 36 \\
\hline & $10-15$ & $4.53 \%$ & 14 \\
\hline & 15-20 & $0.65 \%$ & 2 \\
\hline & $>20$ & $0.65 \%$ & 2 \\
\hline Total: & & $100 \%$ & 309 \\
\hline \multirow{4}{*}{$\begin{array}{l}\text { What was the most common } \\
\text { reason for prescribing? }\end{array}$} & $\begin{array}{l}\text { Continuation of chronic } \\
\text { diseases therapy }\end{array}$ & $77.9 \%$ & 230 \\
\hline & $\begin{array}{c}\text { Based on own diagnosis, } \\
\text { in the case of a minor } \\
\text { illness }\end{array}$ & $10.2 \%$ & 30 \\
\hline & $\begin{array}{c}\text { At the request of the } \\
\text { patient }\end{array}$ & $10.2 \%$ & 30 \\
\hline & Other & $1.7 \%$ & 5 \\
\hline Total: & & $100 \%$ & \\
\hline \multirow{5}{*}{$\begin{array}{l}\text { Do you think the current rules } \\
\text { governing pharmaceutical } \\
\text { prescriptions are clear and } \\
\text { transparent? }\end{array}$} & Definitely yes & $2.6 \%$ & 8 \\
\hline & Rather yes & $44.7 \%$ & 138 \\
\hline & Difficult to say & $19.4 \%$ & 60 \\
\hline & Rather not & $22.3 \%$ & 69 \\
\hline & Definitely not & $11.0 \%$ & 34 \\
\hline Total: & & $100 \%$ & 309 \\
\hline \multirow{3}{*}{$\begin{array}{l}\text { Do you feel that there is abuse of } \\
\text { prescriptions by pharmacists? }\end{array}$} & Yes & $12.3 \%$ & 38 \\
\hline & No & $64.1 \%$ & 198 \\
\hline & I do not know & $23.6 \%$ & 73 \\
\hline Total: & & $100 \%$ & 309 \\
\hline
\end{tabular}

In the conducted survey, respondents were asked if they felt anxious about the act of prescribing, including both pharmaceutical prescriptions and pro auctore and pro familiae prescriptions. More than half of the respondents, i.e., $60.2 \%(n=186)$, had no such concerns, while 117 (37.9\%) admitted to being concerned. The answer "I do not know" was marked by 6 respondents $(1.9 \%)$.

The final question was directed at respondents who confirmed feeling anxious about prescribing, regardless of the type of prescription. They were asked to indicate the reason for their anxiety and the total number of responses obtained in this case is 140 . The most frequently cited reason was ambiguity in the current regulations $(n=78)$, followed by the possibility of harm to the patient as a result of poor judgment $(n=30)$. Concerns about control activities carried out by the National Health Fund and the Province Pharmaceutical Inspectorate were also indicated (9 responses). The lack of substantive preparation for independent prescribing fills 7 respondents with anxiety, and 3 fear conflicts with physi- 
cians. The remaining single responses placed by the respondents in the questionnaire are presented in the table below (Table 4).

Table 4. Distribution of responses to the question about what the perceived concerns about prescribing are.

\begin{tabular}{|c|c|c|}
\hline $\begin{array}{l}\text { What are the Concerns about } \\
\text { Pharmacist Prescribing? }\end{array}$ & Number of Responses & Percentage of Responses \\
\hline Lack of substantive preparation & 7 & $5.0 \%$ \\
\hline Conflicts with doctors & 3 & $2.1 \%$ \\
\hline $\begin{array}{l}\text { The potential for harm to the patient } \\
\text { as a result of poor judgment }\end{array}$ & 30 & $21.4 \%$ \\
\hline Ambiguities in the current legislation & 78 & $55.7 \%$ \\
\hline Control by NFZ */WIF ** & 9 & $6.4 \%$ \\
\hline All the answers & 2 & $1.4 \%$ \\
\hline Abuse of prescriptions by patients & 3 & $2.1 \%$ \\
\hline $\begin{array}{l}\text { My assessment of whether a lack of } \\
\text { medication is a health risk versus the } \\
\text { assessment of a possible controller }\end{array}$ & 1 & $0.7 \%$ \\
\hline $\begin{array}{l}\text { Lack of a review of the prescribed } \\
\text { medication history }\end{array}$ & 2 & $1.4 \%$ \\
\hline No remuneration for prescribing & 1 & $0.7 \%$ \\
\hline $\begin{array}{l}\text { Other answer (combinations of } \\
\text { several of the above) }\end{array}$ & 4 & $2.9 \%$ \\
\hline Total & 140 & $100.0 \%$ \\
\hline
\end{tabular}

\section{Discussion}

The COVID-19 pandemic revealed the need for a well-prepared, highly integrated health system that responds effectively to emergencies. Pharmacists have proven themselves in many roles that allow them to use their knowledge and expertise on the front lines of disasters and epidemics [14]. When restructuring health services to respond to the current public health crisis, it is essential that, following a review of existing services, the hitherto unrealized potential of pharmacists is fully realized [15]. Following the legal changes, the expanded entitlements regarding prescribing have been used in Poland for a relatively short period of time, so there is a lack of concrete research towards actual pharmacy practice in this area. This study is the first to address this topic. The survey yielded a relatively large number of responses in less than 2 months, which proves the interest of Polish pharmacists in the discussed topics. The study revealed the practical conditions of pharmaceutical prescription, as well as the concerns of the pharmacy community about the use of this tool.

In the group of respondents employed in community pharmacies, $75.6 \%$ had issued a prescription to a patient in the pharmacy, indicating that pharmacists mostly use this entitlement. Of the remaining respondents of this group (24.4\%), it is not known for what reason the respondents chose not to write a prescription-perhaps some of them had not yet encountered a situation where a patient needed such a pharmaceutical service. A retrospective study using data collected by the Provincial Pharmaceutical Inspectorate, conducted in 2020, showed that during the 17 years of the previous legal status in force (2002-2019), only 2189 pharmaceutical prescriptions were issued in one particular province ( 842 pharmacies). After the introduction of legislation in 2020 for pharmacist prescribing practices in 
the study region, a steady increase in the number of prescriptions issued by pharmacists was observed. In the period from April to September 2020, over 18,500 pharmaceutical prescriptions were recorded in the same area [2].

One of the most common problems identified in relation to pharmaceutical prescribing is the lack of adequate funding from the public budget. The lack of coverage of this service by reimbursement rules was the main reason why pharmacists in the UK qualified to do so did not use this prescribing entitlement [11]. Despite general awareness of the benefits of providing pharmaceutical services, there are significant limitations on public coverage. In the United States, only pharmacist activities, such as drug reviews, that are related to conducting a Medication Therapy Management (MTM) program may be reimbursed. However, providing pharmaceutical consultations or interfering in the self-medication process of patients is not subject to financing. In Canada, on the other hand, pharmaceutical prescribing is covered by the reimbursement system in only two provinces [16]. However, according to the current legislation, pharmaceutical prescriptions cannot be reimbursedtherefore the respondents were asked whether they think a pharmacist should be able to have this option. Based on the obtained results, it is difficult to determine the prevailing attitude of pharmacists in this regard. Admittedly, nearly half (49.5\%) of the respondents believe that such a possibility should be available, while $39.8 \%$ are of the opposite opinion and the remaining $10.7 \%$ have no opinion on this issue.

In the current state of the law in Poland, only pro auctore and pro familiae prescriptions can be issued on a reimbursement basis. However, also in the case of these prescriptions, pharmacists in Poland remain cautious when deciding on the payment of the prescription.

The results of this study show that pharmacists are keen to make use of the permission granted to prescribe for themselves. Most of respondents $(83.5 \%)$ issued a pro auctore prescription, and slightly less, $(76.4 \%)$ issued a prescription for a family member. In addition, most of the respondents admitted to issuing both prescriptions $(71.5 \% ; n=221)$. Most of these prescriptions were fully paid, despite the possibility of reimbursement. The propensity to prescribe reimbursed drugs is higher for pro familiae prescriptions than for pro auctore prescriptions (26.2\% compared to $18.7 \%$ ).

The relatively low proportion of prescriptions including reimbursement may be due to fear of unfavorable interpretation by the controlling authorities (NFZ, WIF), which was pointed out by $7.8 \%$ of respondents in a further question regarding concerns (Table 3 ). The rules of drug reimbursement in Poland are quite complicated. The right to reimbursement of a given drug depends on the medical indication. The medical indication can be related to the setting of an appropriate diagnosis. Unfortunately, Polish pharmacists, despite extended prescription entitlements, do not have official diagnostic competences.

Prescribing medicines for oneself and one's relatives raises questions. On the one hand, this practice saves time and reduces the potential costs associated with consulting another specialist. On the other hand, the emotional connection leads to a greater risk of overlooking important symptoms and, consequently, making a misdiagnosis. As with all prescriptions, the pharmacist may be the first and last qualified health care professional with whom a consultation is possible when a pro auctore prescription is filled by a health care professional. When considering authorizing a pharmacist to prescribe medicines for themselves, the potential risk of abuse is increased for several reasons: general knowledge of drug products and the confidence in their own judgment that goes with this, easy access to most preparations in the pharmacy, and long hours that discourage the extra effort of visiting a physician [17]. In a New York City survey of pharmacists $(n=131)$, most admitted to prescribing for themselves, and the most common reasons included the belief that a doctor would prescribe the exact same drug. Despite the acknowledgement of the prevalence of this practice, prescribing prescription-only drugs without medical supervision has been considered unprofessional and illegal [18]. However, the data on prescriptions for the prescribers themselves are not strictly controlled and if there are any irregularities in this area, they are only resolved when complaints are recorded [19] or by a 
challenge to the reimbursement by the relevant institution, which in Poland is the National Health Fund (NFZ).

Most of the surveyed pharmacists $(74.8 \%)$ issue between 1 and 5 prescriptions a month on average. This result suggests that pharmacists are very cautious about their new rights. In the UK, pharmacists with newly acquired privileges also initially took a cautious approach to their prescribing role [20]. At the same time, such an attitude may indicate prudence and a strong sense of professional responsibility.

In the previous state of the law, pharmaceutical prescriptions in Poland could basically only apply to life-saving drugs. Interestingly, in the question identifying the most common reason for a pharmacist's prescription, no one indicated such drugs in their response. The results show that pharmacists are most willing to prescribe a drug as a continuation of therapy (74.4\% of respondents). Data from a survey conducted in 2020 show that for a period of 7 months (April-September 2020), the highest percentage of prescriptions were those used for diseases of the cardiovascular system, the gastrointestinal tract and metabolic disorders, the nervous system, and those used in dermatological diseases [2].

Abroad, repeat prescriptions are written by pharmacists very frequently-a system of repeat dispensing for certain chronic medicines exists in Australia, New Zealand, Canada, the Netherlands, and the UK [21]. Pharmacists with prescribing authority are able to achieve similar clinical outcomes as physicians, including blood pressure control, medication adherence, and patient satisfaction in terms of the quality of health care [22].

It should be emphasized that Polish pharmacists usually do not have access to the official medical records of the patient. However, a chronically ill patient's need for access to appropriate medications is relatively easy to verify. The pharmacist may ask to see the previous doctor's prescription; moreover, he may recognize the patient who constantly buys the given drugs in his pharmacy, and in the case of relatives (pro familiae prescription), he is aware of the treatment being provided on the basis of personal relations. At the time of the survey, the decision to prescribe repeat prescriptions was undoubtedly facilitated by a general awareness of the difficult access to physicians due to the epidemic situation and the fact that discontinuing long-term therapy is a health risk.

The dynamics of legal changes, not only in social, but also in professional functioning, may contribute to the difficult assimilation of new regulations. Less than half of the survey participants (47.3\%) believe that the current pharmaceutical prescribing regulations are clear and transparent, while one-third of the respondents $(33.3 \%)$ do not perceive the introduced regulations as understandable. This makes it impossible to determine how favorably Polish pharmacists feel about the content of the introduced legal changes. Furthermore, no significant differences were found in relation to experience, with expected different opinions of young versus more experienced pharmacists.

The profession of a pharmacist is a profession of public trust. As such, pharmacists are subject not only to criminal and civil liability, but also professional liability. In the context of the new entitlements, the majority (64.1\%) of pharmacists interviewed do not believe that there is any abuse of their prescribing powers. The risk of over-reaping the benefits of looser regulations may be greater from chain pharmacy owners than from pharmacists themselves. An example of undesirable behavior was the controversial use of a pharmaceutical prescription as a means of advertising a pharmacy-which resulted in a fine of PLN 40,000 (around USD 10,000) being imposed by the Pomeranian Pharmaceutical Inspectorate (WIF) in Gdansk [23]. The advertising of a community pharmacy in Poland is not allowed [8]. Moreover, according to the Code of Ethics of a Pharmacist of the Republic of Poland, market mechanisms, social pressures, or administrative requirements do not exempt a pharmacist from observing the principles of professional ethics [24].

Based on the experiences of UK and Canadian pharmacists, the greatest difficulties in making prescribing decisions included lack of confidence, risk of error, limited access to the full clinical picture, lack of prescribing experience, and in addition, inadequate levels of communication with patients as well as physicians. Barriers to pharmacist prescribing also include lack of proper procedures for managing pharmaceutical prescriptions, lack of 
subsidies for prescribing, potential conflict with other pharmacist duties, and interference in a professional area dominated by physicians [11]. Pharmacists have been shown to be confident in their independent prescribing [13]. In contrast, physicians were less favorable towards assigning such a function to pharmacists, with inadequate preparation in the area of clinical trials mainly indicated [25].

In this conducted survey, $37.9 \%$ of the respondents admitted that they felt apprehensive about their prescriptions. Among the most frequently indicated concerns were ambiguities in the current regulations (55.7\%), which may result from the fact that the new entitlements were granted relatively recently (01.04.2020) and only from 15.05.2020 was the application enabling the issuance of e-prescriptions launched. This was followed by respondents who marked the possibility of harm to the patient as a result of misjudgment $(21.4 \%)$, which may be due to a lack of appropriate professional training. Moreover, several respondents felt more than one concern regarding prescribing (Table 3).

There are several limitations in this study that may affect the objectivity and reliability of the results obtained. The group of 308 surveyed pharmacists accounted for $0.85 \%$ of the total number of people meeting the survey criteria. Currently, 36,482 pharmacists with an active license to practice are entered in the register of pharmacists. To achieve the sample size recommended by the Sample Size Calculator, made available by the platform http:/ / www.raosoft.com/ [26], the study group should have at least 381 respondents (confidence level: 95\%, margin of error: 5\%). The current number of respondents increases the margin of error to $5.56 \%$. In addition, the form of only online distribution of the questionnaire did not allow any doubts related to the questions to be dispelled, as well as limiting the group of potential respondents to people actively using the Internet.

\section{Conclusions}

The amendment of the regulations on pharmaceutical prescription undoubtedly brings benefits both to patients and pharmacists. The privilege of prescribing raises the profile of the profession while providing a vehicle for pharmaceutical care. By elevating the role of pharmacists in the health care system, it is possible to increase the fluidity of health care services while relieving other medical professions. The results of the survey showed that pharmacists in Poland willingly but cautiously use the extended prescribing entitlements. The main reason for this is that the existing regulations are not fully clear to prescribers, therefore they should be made more specific and uniform. The most common reason identified by pharmacists for prescribing was the continuation of therapy, so a further development of the rights discussed could be a repeat prescription. Nonetheless, further research is needed to completely explore the realities and benefits regarding the expertise of prescribing pharmacists.

Supplementary Materials: The following supporting information can be downloaded at: https:// www.mdpi.com/article/10.3390/ijerph19031648/s1. Survey questionnaire attached as an Appendix.

Author Contributions: Conceptualization J.M., A.Z.; methodology J.M., A.Z.; software J.M., A.Z.; validation A.Z., formal analysis J.M.; investigation, J.M.; resources, J.M., A.Z., N.W.; data curation J.M.; writing—original draft preparation J.M.; writing—review and editing, A.Z., N.W.; visualization N.W.; supervision A.Z.; project administration A.Z.; funding acquisition N.W. All authors have read and agreed to the published version of the manuscript.

Funding: This research received no external funding.

Institutional Review Board Statement: Not applicable.

Informed Consent Statement: Not applicable.

Data Availability Statement: Not applicable.

Conflicts of Interest: The authors declare no conflict of interest. 


\section{References}

1. Act from the Polish Journal of Laws. The Polish Pharmaceutical Law Act of 6 September 2001. (JL No. 126, Item 1381) Consolidated Text of 15 March 2019 (JL item 499) and Consolidated Text of 28 May 2021 (JL item 974). Available online: https:/ /isap.sejm.gov.pl/isap.nsf/DocDetails.xsp?id=WDU20011261381 (accessed on 29 November 2021).

2. Zimmermann, A.; Płaczek, J.; Wrzosek, N.; Owczarek, A. Assessment of Pharmacists Prescribing Practices in Poland-A Descriptive Study. Healthcare 2021, 9, 1505. [CrossRef] [PubMed]

3. Act of 22 July 2014 Amending the Act on the Profession of Nurse and Midwife and Some Other Acts (Polish Journal of Laws of 2014, item 1136). Available online: https:/ / isap.sejm.gov.pl/isap.nsf/DocDetails.xsp?id=WDU20140001136 (accessed on 29 November 2021).

4. Merks, P.; Jakubowska, M.; Drelich, E.; Świeczkowski, D.; Bogusz, J.; Bilmin, K.; Sola, K.F.; May, A.; Majchrowska, A.; Koziol, M.; et al. The legal extension of the role of pharmacists in light of the COVID-19 global pandemic. Res. Soc. Adm. Pharm. 2021, 17, 1807-1812. [CrossRef] [PubMed]

5. Act of 31 March 2020 Amending Certain Acts in the Field of the Health Care System Related to Preventing, Counteracting and Combating COVID-19 (Polish Journal of Laws of 2020, item 567). Available online: https:/ /isap.sejm.gov.pl/isap.nsf/DocDetails. xsp?id=WDU20200000568 (accessed on 29 November 2021).

6. Announcement on Prescriptions Issued by Pharmacists-Ezdrowie.Gov.Pl. Available online: https://ezdrowie.gov.pl/portal/ artykul/komunikat-w-sprawie-recept-wystawianych-przez-farmaceutow (accessed on 1 December 2021).

7. Patryn, R.; Drozd, M. Issuing Prescriptions by the pharmacists to ensure continuity of medical treatment. Legal principles concerning a new typology of prescription. Acta Pol. Pharm. 2021, 78, 151-156.

8. Act of 10 December 2020 on the Profession of Pharmacist (Polish Journal of Laws of 2021, Item 97). Available online: http: / / isap.sejm.gov.pl/isap.nsf/DocDetails.xsp?id=WDU20210000097 (accessed on 29 November 2021).

9. Tsuyuki, R.T.; Watson, K.E. Why pharmacist prescribing needs to be independent. Can. Pharm. J. 2020, 153, 67-69. [CrossRef] [PubMed]

10. Emmerton, L.; Marriott, J.; Bessell, T.; Nissen, L.; Dean, L. Pharmacists and prescribing rights: Review of international developments. J. Pharm. Pharm. Sci. 2005, 8, 217-225. [PubMed]

11. Zhou, M.; Desborough, J.; Parkinson, A.; Douglas, K.; McDonald, D.; Boom, K. Barriers to pharmacist prescribing: A scoping review comparing the UK, New Zealand, Canadian and Australian experiences. Int. J. Pharm. Pract. 2019, 27, 479-489. [CrossRef] [PubMed]

12. Woit, C.; Yuksel, N.; Charrois, T.L. Competence and confidence with prescribing in pharmacy and medicine: A scoping review. Int. J. Pharm. Pract. 2020, 28, 312-325. [CrossRef] [PubMed]

13. Courtenay, M.; Deslandes, R.; Harries-Huntley, G.; Hodson, K.; Morris, G. Classic e-Delphi survey to provide national consensus and establish priorities with regards to the factors that promote the implementation and continued development of non-medical prescribing within health services in Wales. BMJ Open 2018, 8, e024161. [CrossRef] [PubMed]

14. Aburas, W.; Alshammari, T.M. Pharmacists' roles in emergency and disasters: COVID-19 as an example. Saudi Pharm. J. 2020, 28, 1797-1816. [CrossRef] [PubMed]

15. Cadogan, C.A.; Hughes, C.M. On the frontline against COVID-19: Community pharmacists' contribution during a public health crisis. Res. Soc. Adm. Pharm. 2021, 17, 2032-2035. [CrossRef] [PubMed]

16. Mossialos, E.; Courtin, E.; Naci, H.; Benrimoj, S.; Bouvy, M.; Farris, K.; Noyce, P.; Sketris, I. From 'retailers' to health care providers: Transforming the role of community pharmacists in chronic disease management. Health Policy 2015, 119, 628-639. [CrossRef] [PubMed]

17. Sharif, S.I.; Bugaighis, L.M.T.; Sharif, R.S. Self-Medication Practice among Pharmacists in UAE. J. Pharm. Pharmacol. 2015, 6, 428-435. [CrossRef]

18. Balbisi, E.A.; Ambizas, E.M. Self-prescribing of noncontrolled substances among pharmacists. Am. J. Health-Syst. Pharm. 2005, 62, 2508-2511. [CrossRef] [PubMed]

19. Moberly, T. Physician, don't heal thyself: The perils of self prescribing. BMJ 2014, 349, g7401. [CrossRef] [PubMed]

20. Mcintosh, T.; Munro, K.; Mclay, J.; Stewart, D. A cross sectional survey of the views of newly registered pharmacists in Great Britain on their potential prescribing role: A cautious approach. Br. J. Clin. Pharmacol. 2012, 73, 656-660. [CrossRef] [PubMed]

21. Merks, P.; Byliniak, M.; Olszewska, A.; Świeczkowski, D.; Paluch, A.; Śliwa, R.; Słomiak, K.; Kaźmierczak, J.; Krupa, K.; Krysiński, J. Pharmaceutical service-repeating prescriptions as a way to integrate the medical and pharmaceutical communities. Farm. Pol. 2015, 71, 574-585.

22. Weeks, G.; George, J.; Maclure, K.; Stewart, D. Non-medical prescribing versus medical prescribing for acute and chronic disease management in primary and secondary care. Cochrane Database Syst. Rev. 2016, 11, 1-55. [CrossRef] [PubMed]

23. PLN 40,000 Fine for a Stumbler in front of a Pharmacy. He Encouraged Questions about a Pharmaceutical Prescription ... -Farmacja.Pl. Available online: https://farmacja.pl/40-000-zl-kary-za-potykacz-przed-apteka-zachecal-do-pytania-o-receptefarmaceutyczna / (accessed on 2 December 2021).

24. The Code of Ethics of the Pharmacist of the Republic of Poland. Resolution No. VI / 25/2012 of January 22, 2012 of the 6th National Congress of Pharmacists. Available online: https:/ /www.nia.org.pl/kodeks-etyki/ (accessed on 29 November 2021). 
25. Stewart, D.C.; George, J.; Bond, C.M.; Diack, H.L.; McCaig, D.J.; Cunningham, S. Views of pharmacist prescribers, doctors and patients on pharmacist prescribing implementation. Int. J. Pharm. Pract. 2009, 17, 89-94. [CrossRef] [PubMed]

26. Sample Size Calculator by Raosoft, Inc. Available online: http:/ / www.raosoft.com/samplesize.html (accessed on 27 May 2021). 